\title{
Recent advances in alcoholic hepatitis
}

\author{
Jennifer Veryan, ${ }^{1}$ EH Forrest (i) ${ }^{1,2}$
}

${ }^{1}$ Liver Unit, Glasgow Royal

Infirmary, Glasgow, UK

${ }^{2}$ College of Medicine, Veterinary

and Life Sciences, University of

Glasgow, Glasgow, UK

\section{Correspondence to}

Dr EH Forrest, Glasgow Royal

Infirmary, Glasgow, UK; ewan.

forrest@ggc.scot.nhs.uk

Received 1 February 2019

Revised 7 April 2019

Accepted 29 April 2019

Published Online First

21 May 2019

\section{Check for updates}

(c) Author(s) (or their employer(s)) 2020. No commercial re-use. See rights and permissions. Published by BMJ.

To cite: Veryan J, Forrest EH. Frontline Gastroenterology 2020;11:133-139.

\section{ABSTRACT}

Alcoholic hepatitis $(\mathrm{AH})$ is an acute deterioration in liver function seen in the context of prolonged excessive alcohol consumption and is characterised by the rapid onset of jaundice. The diagnosis of $\mathrm{AH}$ has been controversial for many years: it is now accepted that there are clear clinical criteria which can be used to diagnose $\mathrm{AH}$ without the need for a liver biopsy. Corticosteroids remain the only treatment proven to be effective in reducing short-term mortality in severe $\mathrm{AH}$; abstinence from alcohol is the most important factor in determining longterm survival. It is recommended a trial of corticosteroid therapy is considered only in those patients with high baseline 'static' scores (Glasgow Alcoholic Hepatitis score and model for end-stage liver disease). Response to corticosteroid therapy should be assessed using a 'dynamic' score such as the Lille score at day 7 , with corticosteroids continuing only in patients with a favourable score. Infection and acute kidney injury are associated with poorer outcomes in $\mathrm{AH}$. Early screening for and treatment of infection is recommended with antibiotic therapy overlapping with any subsequent corticosteroid treatment. A biomarker which predicts benefit from corticosteroids at baseline would avoid a trial of therapy to determine response. More efficacious therapeutic options for $\mathrm{AH}$ patients are required with $\mathrm{N}$-acetylcysteine, granulocyte colony stimulating factor, faecal microbiota transplantation and routine antibiotics showing promise, but adequate controlled trials are needed to confirm efficacy. Liver transplant has an emerging role for some patients with severe $\mathrm{AH}$ not responding to corticosteroids and is likely to become more acceptable with improved methods of patient selection.

\section{INTRODUCTION}

Alcohol-related liver disease (ArLD) is an important cause of morbidity and mortality worldwide, and encompasses a spectrum of liver injury, including steatosis, acute alcoholic hepatitis ( $\mathrm{AH})$ and chronic fibrosis leading to cirrhosis. $\mathrm{AH}$

\section{Key points}

- 'Probable' alcoholic hepatitis (AH) can be diagnosed based on clinical and laboratory criteria-updated European Association for the Study of the Liver and American College of Gastroenterology guidelines now recommend liver biopsy is only required in cases of diagnostic uncertainty.

- Early screening for and treatment of infection is recommended: antibiotic therapy should overlap with any subsequent corticosteroid treatment.

- Corticosteroids remain the only therapy proven to improve short-term survival-a trial of steroids should be considered in patients with high baseline 'static' scores.

- A day 7 Lille score should be calculated for all patients started on corticosteroids; corticosteroids should continue only in patients with a favourable Lille score $(<0.45)$.

- Infection and acute kidney injury are associated with poorer outcomes in $\mathrm{AH}$.

- Liver transplant is increasingly recognised as an effective treatment for select patients with severe $\mathrm{AH}$ not responding to corticosteroid therapy.

- Abstinence from alcohol is key in determining long-term survival in $\mathrm{AH}$.

is a clinical syndrome of an acute severe deterioration in liver function with jaundice in patients drinking alcohol excessively, the majority of whom will already have established cirrhosis. Jaundice develops rapidly and can be progressive with a systemic inflammatory response. Accurate data on the incidence of $\mathrm{AH}$ is difficult to obtain as many cases will be coded more generally under ArLD or other complications of liver disease. However, data from Scotland indicates that $\mathrm{AH}$ accounts for $12 \%$ of all ArLD hospital admissions and that $14 \%$ of new patients admitted with ArLD have AH. ${ }^{1}$

$\mathrm{AH}$ is associated with high shortterm mortality. While the past few decades have seen an improvement in 
Table 1 Diagnostic criteria for 'probable' alcoholic hepatitis (from Crabb et al, 20164)

\begin{tabular}{|c|c|}
\hline \multicolumn{2}{|l|}{ Clinical criteria } \\
\hline Alcohol & $\begin{array}{l}\text { Excessive alcohol consumption for } \geq 6 \text { months } \\
\text { Men: }>4 \text { drinks (approx. } 50-60 \mathrm{~g} \text { alcohol)/day } \\
\text { Women: }>3 \text { drinks (approx. } 40 \mathrm{~g} \text { alcohol)/day }\end{array}$ \\
\hline Abstinence & $<60$ days before onset of jaundice \\
\hline Jaundice & $<8$ weeks duration \\
\hline \multicolumn{2}{|l|}{ Laboratory criteria } \\
\hline Bilirubin & $>3 \mathrm{mg} / \mathrm{dL}(50 \mu \mathrm{mol} / \mathrm{L})^{*}$ \\
\hline AST IU/L & $>50$ \\
\hline AST:ALT ratio & $>1.5$ \\
\hline AST and ALT (IU/L) & Both $<400$ \\
\hline $\begin{array}{l}\text { Other causes of liver } \\
\text { disease excluded }\end{array}$ & $\begin{array}{l}\text { Viral hepatitis, biliary obstruction, autoimmune liver } \\
\text { disease and Wilson disease }\end{array}$ \\
\hline
\end{tabular}

*See text for authors' comment.

ALT, alanine aminotransferase; AST, aspartate aminotransferase.

liver disease-related outcomes in general, definitive evidence of improvement in mortality in $\mathrm{AH}$ is difficult to find, as the diagnostic and trial inclusion criteria have changed over time. Recent large studies suggest mortality less than $20 \%$ at 28 days and approximately $30 \%$ at 90 days for untreated patients. ${ }^{2}$

\section{Diagnosis}

AH is largely a clinical diagnosis. Liver biopsy can be performed but variable rates of histological confirmation of a clinical $\mathrm{AH}$ are reported in cohort studies. The diagnosis is confirmed in more than $95 \%$ of cases where there are clear clinical criteria for the diagnosis based on a minimum level of serum bilirubin. ${ }^{3}$ This has led to the National Institute for Alcohol Abuse and Alcoholism recommending criteria for a diagnosis of 'probable' AH without the need for a biopsy to guide inclusion of patients into phase III trials (table 1), but which can also be applied to clinical practice. ${ }^{4}$ The authors of this review believe that the threshold of bilirubin at $3 \mathrm{mg} / \mathrm{dL}(50 \mu \mathrm{mol} / \mathrm{L})$ is probably too low and a figure of nearer $5 \mathrm{mg} / \mathrm{dL}(80-85 \mu \mathrm{mol} / \mathrm{L})$ is probably more reflective of the published literature.

In this context, the tone of international recommendations regarding biopsy in AH has softened. In 2012 the European Association for the Study of the Liver (EASL) guidelines required a biopsy for diagnosis, however, in 2018 the updated guidelines indicate that 'biopsy must only be performed in cases where there is diagnostic uncertainty'. ${ }^{5}$ The 2018 American College of Gastroenterology (ACG) guidelines are also in keeping with this approach. ${ }^{6}$ Thus with clear clinical criteria, biopsy can be avoided in most cases of $\mathrm{AH}$.

\section{Evaluating severity and predicting prognosis in $\mathrm{AH}$}

The modified Maddrey's discriminant function ( $\mathrm{mDF}$ ), Glasgow alcoholic hepatitis score (GAHS), the Age, Bilirubin, International Normalised Ratio (INR) and Creatinine (ABIC) score and the model for end-stage liver disease (MELD: SUnited Network for Organ
Sharing variant) score are 'static' scores which predict prognosis based on variables identified at a single point in time (table 2).

A recent analysis of prognostic scores using Steroids or Pentoxifylline for Alcoholic Hepatitis (STOPAH) trial data showed that the $\mathrm{mDF}$ was significantly less predictive than the GAHS, ABIC and MELD for both 28-day and 90-day outcomes. ${ }^{7}$ The 2018 EASL guidelines suggest considering treatment with a high mDF ( $\geq 32$ ) or GAHS $(\geq 9)$; the 2018 ACG guidelines suggest the use of high $\mathrm{mDF}(\geq 32)$ or high MELD $(\geq 21)$. However, concerns exist regarding the accuracy of laboratory-based variables: creatinine measurement becomes inaccurate with hyperbilirubinaemia, and there is interlaboratory variation in the measurement of prothrombin time and INR. This may lead to a variation in MELD values of between 2 and 12 points. ${ }^{8}$

The GAHS has been criticised as being a categorical score and therefore prone to misclassification of patients relative to continuous scores such as the MELD. However, for any prognostic score to be clinically useful, thresholds for outcome need to be specified and thus the calibration of a score is as important as its discrimination. The mDF is a very sensitive score and therefore risks identifying and treating many patients with mild disease. Although a MELD of 21 is reasonable at determining prognosis, it is not yet clear that it identifies therapeutic benefit. ${ }^{9}$

\section{'Dynamic' scores}

These scores incorporate the change in serum bilirubin levels after a period of corticosteroid treatment to assess corticosteroid response. The most commonly used score is the Lille score (table 2). ${ }^{10}$ This score is both prognostic and also indicative of treatment 'response'. The original Lille score assessed the change in bilirubin over a week of treatment, but a day 4 Lille score has been shown to be useful. ${ }^{11}$

\section{Combination of 'static' and 'dynamic' scores}

There is mounting evidence to suggest that mortality in $\mathrm{AH}$ is better predicted using a combination of 'static' and 'dynamic' scoring systems such as the MELD plus Lille model. ${ }^{12}$ Such combination is intuitively more likely to predict outcome: a patient who is unwell at baseline and who deteriorates despite treatment is likely to have a poor outcome. However, the combination of MELD and Lille runs the risk of 'doublecounting' of prognostic variables: both scores include measures of initial prothrombin time, renal function and serum bilirubin; only the age, serum albumin and change in bilirubin are unique to the Lille score.

Clinical experience indicates that $\mathrm{AH}$ is itself a dynamic condition: some patients worsen after admission while others show spontaneous improvement. Therefore, it is important to monitor 'static' scores as a patient with a low value may evolve a higher score and be considered for therapeutic intervention. 


\begin{tabular}{|c|c|c|c|c|c|c|}
\hline Score & Variables & \multicolumn{4}{|l|}{ Calculation } & Interpretation \\
\hline$m D F$ & $\begin{array}{l}\text { Prothrombin time } \\
\text { (PT), control PT and } \\
\text { bilirubin }\end{array}$ & \multicolumn{4}{|c|}{ (4.6×(patient's PT-control PT))+bilirubin (mg/dL) or (bilirubin $(\mu \mathrm{mol} / \mathrm{L}) / 17)$} & Severe disease: $\geq 32$ \\
\hline \multirow[t]{6}{*}{ GAHS } & \multirow{6}{*}{$\begin{array}{l}\text { Age, } \mathrm{WCC} \text {, urea, } \mathrm{PT} \\
\text { ratio/INR, bilirubin }\end{array}$} & & 1 & 2 & 3 & \multirow[t]{6}{*}{ Severe disease: $\geq 9$} \\
\hline & & Age & $<50$ & $\geq 50$ & & \\
\hline & & WCC $\left(10^{9} / \mathrm{L}\right)$ & $<15$ & $\geq 15$ & & \\
\hline & & Urea (mmol/L) & $<5$ & $\geq 5$ & & \\
\hline & & $\mathrm{PTr} / \mathrm{INR}$ & $<1.5$ & $1.5-2.0$ & $>2.0$ & \\
\hline & & Bilirubin (umol/L) & $<125$ & $125-250$ & $>250$ & \\
\hline MELD & $\begin{array}{l}\text { Bilirubin, creatinine } \\
\text { and INR }\end{array}$ & \multicolumn{4}{|c|}{$3.78 \times \ln ($ serum bilirubin $(\mathrm{mg} / \mathrm{dL}))+11.2 \times \ln (\mathrm{INR})+9.57 \times \ln ($ serum creatinine $(\mathrm{mg} / \mathrm{dL}))+6.43$} & $\begin{array}{l}\text { No clear optimal cut- } \\
\text { off for severe disease; } \\
\text { proposed values } \\
\text { range from } 18 \text { to } 30.5 \\
\text { but } \geq 21 \text { is gaining } \\
\text { acceptancy }\end{array}$ \\
\hline$A B / C$ & $\begin{array}{l}\text { Bilirubin, creatinine, } \\
\text { age and INR }\end{array}$ & \multicolumn{4}{|c|}{ (Age, years $\times 0.1)+($ serum bilirubin, $\mathrm{md} / \mathrm{dL} \times 0.08)+(I N R \times 0.8)+($ serum creatinine, $\mathrm{mg} / \mathrm{dL} \times 0.3)$} & $\begin{array}{l}<6.71 \text { : low risk } \\
6.71-9.0 \text { : intermediate } \\
\text { risk } \\
>9.0 \text { : high risk }\end{array}$ \\
\hline Lille & $\begin{array}{l}\text { Age } \\
\text { albumin day } 0 \text {, } \\
\text { INR day } 0 \text {, } \\
\text { creatinine day } 0 \text {, } \\
\text { bilirubin days } 0 \text { and } 7\end{array}$ & \multicolumn{4}{|c|}{$\begin{array}{l}\mathbf{R}=3.19-(0.101 \times \text { age in years })+(0.147 \times \text { albumin day } 0 \text { in } \mathrm{g} / \mathrm{L})+(0.0165 \times E C B L \text { in } \mu M)- \\
(0.206 \times \text { renal insufficiency })^{*}-(0.0065 \times \text { bilirubin day } 0 \text { in } \mu \mathrm{M})-(0.0096 \times \text { INR }) \\
\text { Score }=\operatorname{EXP}(-R) /(1+E X P(-R))\end{array}$} & $\begin{array}{l}\text { Response: } \\
<0.45 \\
\text { Non-response: } \\
\geq 0.45\end{array}$ \\
\hline \multicolumn{7}{|c|}{$\begin{array}{l}\text { *Renal Insufficiency: Creatinine }>115 \mu \mathrm{M}=1 \text {; Creatinine }<115 \text { uM=0 } \\
\dagger \\
\ddagger\end{array}$} \\
\hline
\end{tabular}

\section{Measuring outcomes in $\mathbf{A H}$}

The most obvious measurement of outcome from $\mathrm{AH}$ is survival. Many studies have used 28-day survival to measure treatment effect, but it is possible to alter the 28-day outcome without affecting the longer term survival. A more relevant outcome is 3-month (90 day) survival. After this time-point, factors other than the AH episode, especially subsequent drinking behaviour, influence the course of a patient's illness. ${ }^{13}$ Therefore the measurement of outcome at 90 days is most reflective of treatment effect in clinical trials.

There has been a tendency in recent literature to conflate the Lille score with outcome: a Lille 'response' being regarded as favourable. The Lille score is itself only an indicator of prognosis and therefore a surrogate marker of outcome: patients with a Lille response may yet die from an episode of $\mathrm{AH}$, and nearly $50 \%$ of those with a Lille non-response will survive.

\section{Infection, acute kidney injury and gastrointestinal bleeding in $\mathrm{AH}$}

Infection is found frequently in patients with severe AH. Previously it was suggested that infection treated before corticosteroid therapy had no influence on outcome, but the development of infection after initiating corticosteroids led to a significant reduction in survival. ${ }^{14}$ More recent analysis from STOPAH suggests that infections treated prior to corticosteroids still influence $\mathrm{AH}$ outcome. ${ }^{15}$ Patients presenting with active infection whose antibiotic therapy overlapped with their corticosteroid therapy had a better outcome relative to those whose antibiotics were stopped prior to corticosteroids (90-day mortality: $13 \%$ vs $52 \%$ ). This study also demonstrated corticosteroid treatment was associated with a greater risk of post-treatment infection (OR 1.70; $\mathrm{p}=0.024)$, and infection in the first 7 days of corticosteroid treatment was associated with Lille non-response.

Acute kidney injury (AKI) is another indicator of poor outcome in $\mathrm{AH}$. In one study, $28 \%$ of $\mathrm{AH}$ patients developed AKI and had a 65\% 90-day mortality as opposed to $7 \%$ for those without AKI. The development of AKI was closely related to the systemic inflammatory response syndrome (SIRS). ${ }^{16} \mathrm{~A}$ recent study has identified three variables associated with the risk of developing AKI: hepatic encephalopathy, SIRS and MELD score on admission. A score (AKI-AH risk score) was derived from these variables, with a high score ( $>4$ ) indicating a 70\% chance of developing AKI during admission. ${ }^{17}$

Patients with ArLD presenting with gastrointestinal bleeding may have clinical features indistinguishable from an episode of $\mathrm{AH}$. These patients seem to have 
a different natural history from $\mathrm{AH}$ patients without gastrointestinal bleeding. They have fewer infections ${ }^{18}$ and this may be attributable to the routine use of antibiotics in the management of GI bleeding in patients with cirrhosis rather than any distinctions between the patient populations, but further studies are required.

\section{Predicting corticosteroid benefit at baseline}

Currently recommended treatment strategies rely on a trial of corticosteroid therapy. Several recent reports suggest it may be possible to identify patients who might benefit from corticosteroids before such exposure. Higher density of Mallory bodies and more severe hepatocyte ballooning on biopsy are associated with non-response. ${ }^{19}$ Alternatively, high circulating levels of bacterial DNA $(>18.4 \mathrm{pg} / \mathrm{mL})$ may predict the development of infection within the first 7 days of corticosteroid therapy and identify non-responders. ${ }^{15}$ A further study found that circulating microvesicles, reflective of oxidative stress, are more numerous and larger in patients with a Lille non-response. ${ }^{20}$ Similarly, higher levels of urinary albumin at baseline has been associated with Lille non-response and lower survival. ${ }^{21}$ There are also indications that the simpler neutrophil-to-lymphocyte ratio may be predictive of corticosteroid effectiveness. ${ }^{22}$ Although promising, as yet none of these indicators can be advocated as indicators for corticosteroid therapy in clinical practice.

\section{$\mathrm{AH}$ as acute-on-chronic liver failure}

Acute-on-chronic liver failure (ACLF) is an evolving concept describing acutely decompensated chronic liver disease with concurrent single or multiple organ failure. $\mathrm{AH}$ is a significant cause of ACLF and in a recent study, $48 \%$ patients were found to have ACLF at the point of diagnosis of severe AH (prevalent ACLF; pACLF), and a further 18\% developed ACLF during follow-up after diagnosis (incidental ACLF; iACLF). ${ }^{23}$ Mortality was significantly higher in those with pACLF and iACLF compared with patients without ACLF. The cumulative incidence of death in patients increased with increasing severity of pACLF, and the Lille response to corticosteroids was also reduced in those with pACLF.

\section{Treatment}

Abstinence

It is important that $\mathrm{AH}$ is considered as two conditions: acute liver injury in a patient with an alcohol use disorder (AUD). Severity of AH determines short-term (within 6 months of starting corticosteroid therapy) outcome, and abstinence from alcohol is the key factor in determining long-term (after 6 months) survival. ${ }^{13}$

The role of pharmacotherapy for AUD in the context of ArLD is beyond the remit of this review but reliance on drug therapy for AUDs is not advised: a multidisciplinary team approach is imperative in order to manage complex psychosocial factors.
General supportive measures

Diuretics should be used with caution and other nephrotoxins avoided. Caution should also be given to the use of non-selective beta-blockers as these have been associated with a higher risk of AKI in a retrospective cohort study, especially in those with a low mean arterial pressure. ${ }^{24}$

\section{Antibiotics}

Patients with AH are highly susceptible to infection, but the role of routine antibiotics in the management of $\mathrm{AH}$ is not yet established. A multicentre doubleblind randomised control trial (RCT) evaluating the efficacy of antibiotic therapy (co-amoxiclav) given in tandem with corticosteroids is currently underway in France (NCT02281929) and should report later this year. Active screening for infection and early treatment is vital.

\section{Nutrition}

Thiamine supplementation should be given to those with or at risk of Wernicke's encephalopathy. Proteincalorie malnutrition is frequent in patients with severe $\mathrm{AH}$ and is associated with poorer outcomes, and maintaining adequate nutrition in patients with severe $\mathrm{AH}$ is a major clinical challenge.

All patients hospitalised with AH should be referred for dietetic assessment. A recent trial of intensive enteral nutrition alone suggested a daily calorie intake $\geq 21.5$ $\mathrm{kcal} / \mathrm{kg}$ of body weight was associated with lower rates of infection and improved outcomes in corticosteroid treated patients, regardless of how this calorie goal was met. ${ }^{25}$ Nasogastric feeding tubes were tolerated poorly in this study, with nearly half of patients withdrawing their feeding tube prematurely. This suggests that the ability to tolerate nutritional support is itself a prognostic marker rather than the nutrition alone altering the outcome of the illness. Irrespective of this, it makes good clinical sense to try to optimise nutrition in $\mathrm{AH}$ patients.

EASL guidelines currently recommend aiming for a daily calorie intake of $35-45 \mathrm{kcal} / \mathrm{kg}$ body weight, and a daily protein intake of $1.2-1.5 \mathrm{~g} / \mathrm{kg}$ of body weight. ${ }^{5}$ There is no good evidence for parenteral nutrition.

Specific pharmacological therapies targeting liver injury: recommended treatment

Corticosteroids (prednisolone $40 \mathrm{mg} /$ day orally or methylprednisolone $32 \mathrm{mg} /$ day intravenously if oral route not possible) have been shown to improve 28 -day survival in severe AH. The 2018 EASL and ACG clinical practice guidelines have moved away from using only the $\mathrm{mDF}$ to define the threshold for such treatment: patients with an $\mathrm{mDF} \geq 32$ or GAHS $\geq 9$ (EASL)/MELD $>20$ (ACG) are considered to have severe AH. The STOPAH trial showed a trend for mortality benefit at 28 days in those treated with corticosteroids compared with those receiving placebo therapy, but this did not extend to 90 days $^{2}$. A subsequent meta-analysis demonstrated a 
reduction in short-term mortality in those treated with corticosteroids. ${ }^{26}$ This was replicated in a further metaanalysis of four controlled trials in 2018, but the survival benefit did not extend beyond 28 days. ${ }^{27}$

Predetermined analysis in STOPAH indicated that those with low baseline 'static' scores (MELD, ABIC and GAHS) derived no therapeutic benefit from corticosteroids. In contrast, when patients presenting with either sepsis or gastrointestinal bleeding, whose natural history may differ from those without such presentations, were excluded, improved 28-day survival was seen in corticosteroid treated patients with high GAHS $(\geq 9)$ and ABIC $(\geq 6.71)$ scores. However, even for these selected patients, there was no survival benefit at 90 days unless associated with a favourable 'dynamic' score. ${ }^{7}$

Evaluation of steroid response at day 7 using the Lille score is recommended. A non-response (Lille score $\geq 0.45$ ) indicates discontinuation of corticosteroid therapy; a response (Lille score $<0.45$ ) indicates continuation for 28 days. An algorithm for management of $\mathrm{AH}$, compatible with current EASL guidelines is suggested in figure 1.

Specific pharmacological therapies targeting liver injury: possible benefit

$\mathrm{N}$-acetylcysteine (NAC) has been studied in combination with other antioxidants in severe $\mathrm{AH}$ without any demonstrable effect on survival. However, given intravenously for the first 5 days of corticosteroid therapy, NAC reduced mortality at 1 month, but not 3 or 6 months in one trial. ${ }^{28}$ The combination of corticosteroids and NAC reduced the incidence of infections and hepatorenal syndrome. A further controlled trial is needed to confirm efficacy before the combination of corticosteroids and NAC can be recommended in clinical practice.

Interest in granulocyte colony stimulating factor (GCSF) in the treatment of severe AH has grown. The earliest RCT compared GCSF with placebo in patients with ACLF (of whom 50\% had AH). Survival at 60 days was significantly higher in the GCSF group with reduced rates of infection and hepatorenal syndrome. ${ }^{29}$ In 2014, another trial studied severe AH treated with either GCSF and pentoxifylline (PTX) or PTX alonesurvival in the group receiving combination therapy was significantly greater than the group treated with PTX alone at 90 days. ${ }^{30}$ These trials included relatively small numbers of patients. A larger trial is required in order to further evaluate the efficacy of GCSF in the treatment of $\mathrm{AH}$.

A recent pilot study assessing the benefit of healthy donor faecal microbiota transplantation (FMT) therapy in patients with severe $\mathrm{AH}$ felt to be ineligible for corticosteroids suggested improved 1-year survival. A subsequent study of patients with severe $\mathrm{AH}$ treated with either nutritional therapy, corticosteroids, PTX or healthy donor FMT demonstrated improved 1-month and 3-month survival in patients treated with FMT compared with the other treatment modalities. ${ }^{31}$ This is another area of AH therapy that requires welldesigned trials rather than more inadequately powered studies which have bedevilled this area of hepatology previously.

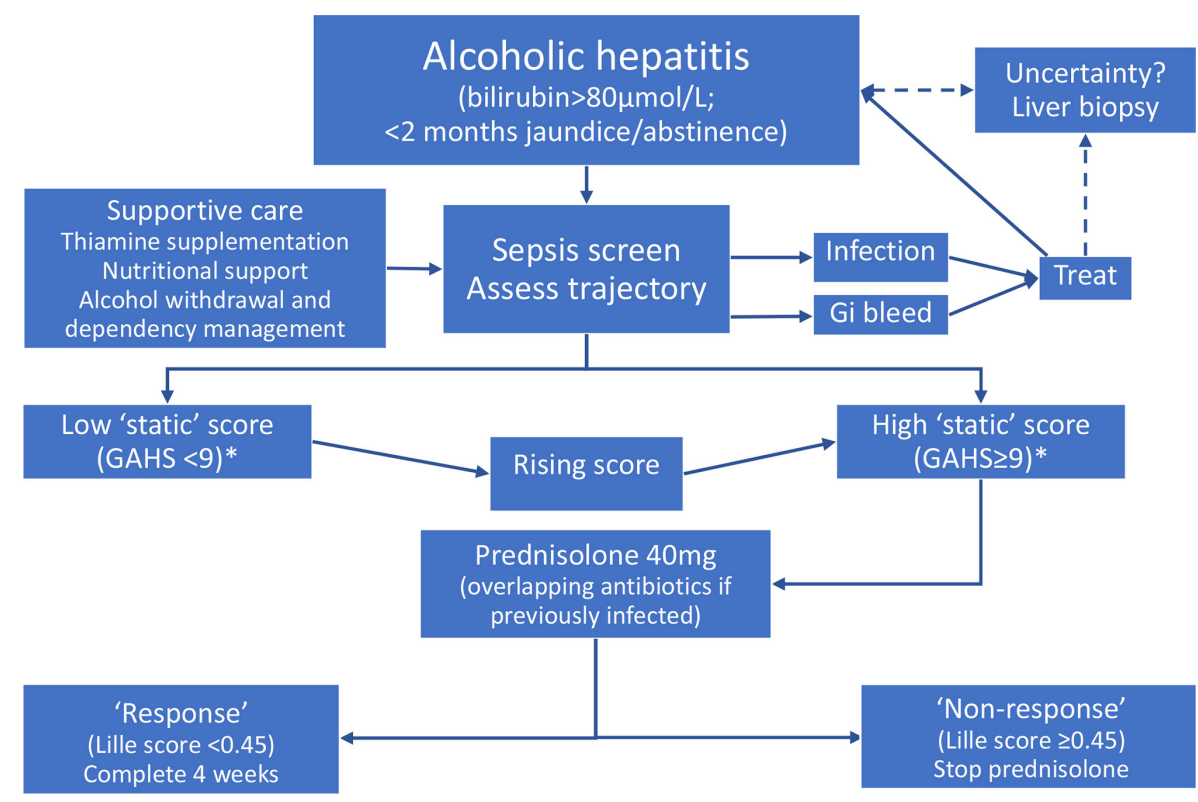

Figure 1 Suggested treatment algorithm: all patients with alcoholic hepatitis should receive supportive care with appropriate management of alcohol withdrawal and general nutritional, as well as specific vitamin, support. A period of assessment to look for and treat infection is vital and this also allows disease trajectory to be determined: rapidly improving liver function suggests specific therapeutic intervention may not be necessary. A high 'static' score indicates potential benefit from corticosteroids although 'response' to these should be assessed after 7 days. 'Responders' continue treatment for 4 weeks; treatment is discontinued in 'non-responders'. *European Association for the Study of the Liver guidelines (2018) also suggest corticosteroid treatment at a threshold of a modified discriminant function $\geq 32$. GAHS: Glasgow Alcoholic Hepatitis score. 
Specific pharmacological therapies targeting liver injury: no evidence of benefit

PTX monotherapy is no longer recommended for the treatment of severe AH. While the initial study comparing PTX with placebo in severe AH was encouraging, ${ }^{32}$ the survival benefit of PTX has not been replicated in subsequent trials, including STOPAH, ${ }^{2}$ and there is no evidence that it is of benefit as a salvage therapy in those with no steroid response. ${ }^{33}$

Extracorporeal liver support has been suggested as a means of giving patients with severe $\mathrm{AH}$ more time for liver regeneration. A subgroup analysis suggested survival was better in younger patients with lower MELD scores $(<28)^{34}$ using the Extracorporeal Liver Assist Device device, but a subsequent study comparing ELAD with standard medical therapy in such patients has shown no survival benefit. ${ }^{35}$

Both infliximab and etanercept have been studied in patients with severe $\mathrm{AH}^{3637}$-increased rates of severe infection and mortality were seen with both drugs and their use is in severe $\mathrm{AH}$ is not recommended.

Results of a recent phase II trial assessing selonsertib (ASK1 inhibitor) in combination with prednisolone in patients with severe $\mathrm{AH}$ were disappointing, with no improvement in liver function or mortality in the combination group compared with prednisolone alone. ${ }^{38}$

\section{Liver transplantation}

Liver transplant (LT) is an effective treatment for patients with liver failure, but its role in patients with severe $\mathrm{AH}$ has been controversial. At the time of writing, $\mathrm{AH}$ is an absolute contraindication to LT in the UK after the lack of success of a Clinical Service Evaluation pilot. However, there is growing evidence that early LT confers a significant survival benefit in patients with severe $\mathrm{AH}$ not responding to corticosteroids. ${ }^{39}$ A recent study has replicated excellent short-term survival and showed similar rates of alcohol relapse compared with patients transplanted for ArLD with 6 months of prior abstinence. ${ }^{40}$ Analysis of this data has led to the Sustained Alcohol use post-LT (SALT) score which looks at four variables: $>10$ drinks/day at initial hospitalisation ( +4 points), multiple prior rehabilitation attempts $(+4$ points), prior alcoholrelated legal issues ( +2 points) and prior illicit substance abuse (+1 point). ${ }^{41}$ A score greater than or equal to 5 had a 95\% negative predictive value for SALT.

The 2018 EASL and ACG clinical practice guidelines ${ }^{5}$ both suggest early LT is considered as salvage therapy in patients with severe $\mathrm{AH}$ not responding to corticosteroids. However, such non-responders have almost 50\% survival and therefore until a more specific measure of adverse prognosis is established, it remains difficult to identify those who are likely to derive greatest benefit from transplantation. Both guidelines stress that a careful selection process including rigorous psychiatric, nutritional and medical comorbidity assessment is required. The data regarding risk of alcohol relapse and survival benefit make it clear transplantation is an option for some patients with $\mathrm{AH}$ - the challenge is identifying those who will benefit and avoiding transplantation in those whose livers will recover. With improved measures of outcome being developed allowing more suitable selection, the role of transplantation for severe AH patients will become increasingly clear.

\section{CONCLUSIONS}

$\mathrm{AH}$ is a florid manifestation of ArLD which can be diagnosed clinically. The $\mathrm{mDF}$ is no longer the optimal scoring system in $\mathrm{AH}$ and patients should be stratified by low and high baseline 'static' scores (GAHS, MELD, ABIC), limiting consideration of corticosteroid therapy to those with high baseline 'static' scores. A baseline biomarker of corticosteroid benefit would allow more targeted therapy. The role of newer therapeutic approaches such as GCSF, NAC, FMT and routine antibiotics need to be clarified, and LT is likely to be an option for selected patients in the future.

Contributors JV and EHF both reviewed the scientific literature and coauthored the manuscript.

Funding The authors have not declared a specific grant for this research from any funding agency in the public, commercial or not-for-profit sectors.

Competing interests Neither JV or EHF have received any funding or have any conflicts of interest with regards to this manuscript.

Patient consent for publication Not required.

Provenance and peer review Commissioned; externally peer reviewed.

ORCID iD

EH Forrest http://orcid.org/0000-0002-7293-2574

\section{REFERENCES}

1 ISD Scotland. Alcohol-related Hospital statistics Scotland 2017/18, 2018. Available: https://www.isdscotland.org/HealthTopics/Drugs-and-Alcohol-Misuse/Publications/2018-11-20/ 2018-11-20-ARHS-Report.pdf [Accessed 27 Jan 2019].

2 Thursz MR, Richardson P, Allison M, et al. Prednisolone or pentoxifylline for alcoholic hepatitis. N Engl J Med Overseas Ed 2015;372:1619-28.

3 Hamid R, Forrest EH. Is histology required for the diagnosis of alcoholic hepatitis? A review of published randomised controlled trials. Gut 2011;60(Suppl 1).

4 Crabb DW, Bataller R, Chalasani NP, et al. Standard definitions and common data elements for clinical trials in patients with alcoholic hepatitis: recommendation from the NIAAA alcoholic hepatitis consortia. Gastroenterology 2016;150:785-90.

5 Thursz M, Gual A, Lackner C. EASL clinical practice guidelines: management of alcohol-related liver disease. $J$ Hepatol 2018;69:154-81.

6 Singal AK, Bataller R, Ahn J, et al. ACG clinical guideline: alcoholic liver disease. Am J Gastroenterol 2018;113:175-94.

7 Forrest EH, Atkinson SR, Richardson P, et al. Application of prognostic scores in the STOPAH trial: discriminant function is no longer the optimal scoring system in alcoholic hepatitis. $J$ Hepatol 2018;68:511-8.

8 Lisman T, Van Leeuwen Y, Adelmeijer J, et al. Interlaboratory variability in assessment of the model of end-stage liver disease score. Liver Int 2008;28:1344-51.

9 Forrest EH, Atkinson SR, Richardson P, et al. ACG clinical guideline for alcoholic liver disease: the MELD threshold 
for corticosteroid treatment has yet to be established. Am J Gastroenterol 2018;11.

10 Louvet A, Naveau S, Abdelnour M, et al. The Lille model: a new tool for therapeutic strategy in patients with severe alcoholic hepatitis treated with steroids. Hepatology 2007;45:1348-54.

11 Garcia-Saenz-de-Sicilia M, Duvoor C, Altamirano J, et al. A Day-4 Lille model predicts response to corticosteroids and mortality in severe alcoholic hepatitis. Am J Gastroenterol 2017;112:306-15.

12 Louvet A, Labreuche J, Artru F, et al. Combining data from liver disease scoring systems better predicts outcomes of patients with alcoholic hepatitis. Gastroenterology 2015;149:398-406.

13 Louvet A, Labreuche J, Artru F, et al. Main drivers of outcome differ between short term and long term in severe alcoholic hepatitis: a prospective study. Hepatology 2017;66:1464-73.

14 Louvet A, Wartel F, Castel H, et al. Infection in patients with severe alcoholic hepatitis treated with steroids: early response to therapy is the key factor. Gastroenterology 2009;137:541-8.

15 Vergis N, Atkinson SR, Knapp S, et al. In Patients With Severe Alcoholic Hepatitis, Prednisolone Increases Susceptibility to Infection and Infection-Related Mortality, and Is Associated With High Circulating Levels of Bacterial DNA. Gastroenterology 2017;152:1068-77.

16 Altamirano J, Fagundes C, Dominguez M, et al. Acute kidney injury is an early predictor of mortality for patients with alcoholic hepatitis. Clin Gastroenterol Hepatol 2012;10:65-71.

17 Sujan R, Cruz-Lemini M, Altamirano J, et al. A validated Score predicts acute kidney injury and survival in patients with alcoholic hepatitis. Liver Transpl 2018;24:1655-64.

18 Rudler M, Mouri S, Charlotte F, et al. Prognosis of treated severe alcoholic hepatitis in patients with gastrointestinal bleeding. J Hepatol 2015;62:816-21.

19 Shasthry SM, Rastogi A, Bihari C, et al. Histological activity score on baseline liver biopsy can predict non-response to steroids in patients with severe alcoholic hepatitis. Virchows Arch 2018;472:667-75.

20 Sukriti S, Maras JS, Bihari C, et al. Microvesicles in hepatic and peripheral vein can predict nonresponse to corticosteroid therapy in severe alcoholic hepatitis. Aliment Pharmacol Ther 2018;47:1151-61.

21 Das S, Hussain MS, Maras JS, et al. Modification patterns of urinary albumin correlates with serum albumin and outcome in severe alcoholic hepatitis. J Clin Gastroenterol 2018.

22 Forrest E, Storey N, Rohit S, et al. Baseline neutrophil to lymphocyte ratio can identify favourable corticosteroid response in alcoholic hepatitis. J Hepatol 2017;66.

23 Sersté T, Cornillie A, Njimi H, et al. The prognostic value of acute-on-chronic liver failure during the course of severe alcoholic hepatitis. J Hepatol 2018;69:318-24.

24 Sersté T, Njimi H, Degré D, et al. The use of beta-blockers is associated with the occurrence of acute kidney injury in severe alcoholic hepatitis. Liver Int 2015;35:1974-82.

25 Moreno C, Deltenre P, Senterre C, et al. Intensive enteral nutrition is ineffective for patients with severe alcoholic hepatitis treated with corticosteroids. Gastroenterology 2016;150:903-10.

26 Singh S, Murad MH, Chandar AK, et al. Comparative effectiveness of pharmacological interventions for severe alcoholic hepatitis: a systematic review and network metaanalysis. Gastroenterology 2015;149:958-70.

27 Louvet A, Thursz MR, Kim DJ, et al. Corticosteroids reduce risk of death within 28 days for patients with severe alcoholic hepatitis, compared with pentoxifylline or Placebo-a meta-analysis of individual data from controlled trials. Gastroenterology 2018;155:458-68.

28 Nguyen-Khac E, Thevenot T, Piquet M-A, et al. Glucocorticoids plus $N$-Acetylcysteine in Severe Alcoholic Hepatitis. N Engl J Med 2011;365:1781-9.

29 Garg V, Garg H, Khan A, et al. Granulocyte ColonyStimulating factor mobilizes CD34+ cells and improves survival of patients with acute-on-chronic liver failure. Gastroenterology 2012;142:505-12.

30 Singh V, Sharma AK, Narasimhan RL, et al. Granulocyte colony-stimulating factor in severe alcoholic hepatitis: a randomized pilot study. Am J Gastroenterol 2014;109:141723.

31 Philips CA, Phadke N, Ganesan K, et al. Corticosteroids, nutrition, pentoxifylline, or fecal microbiota transplantation for severe alcoholic hepatitis. Indian J Gastroenterol 2018;37:215-25.

32 Akriviadis E, Botla R, Briggs W, et al. Pentoxifylline improves short-term survival in severe acute alcoholic hepatitis: a double-blind, placebo-controlled trial. Gastroenterology 2000;119:1637-48.

33 Louvet A, Diaz E, Dharancy S, et al. Early switch to pentoxifylline in patients with severe alcoholic hepatitis is inefficient in non-responders to corticosteroids. J Hepatol 2008;48:465-70.

34 Thompson J, Jones N, Al-Khafaji A, et al. Extracorporeal cellular therapy (ELAD) in severe alcoholic hepatitis: a multinational, prospective, controlled, randomized trial. Liver Transpl 2018;24:380-93.

35 Shakil I. Vital therapies shares dive as liver system fails trial. Reuters, 2018. Available: https://uk.reuters.com/article/usvti-study/vital-therapies-shares-dive-as-liver-system-fails-trialidUKKCN1LS1M9 [Accessed 22 Jan 2019].

36 Naveau S, Chollet-Martin S, Dharancy S, et al. A doubleblind randomized controlled trial of infliximab associated with prednisolone in acute alcoholic hepatitis. Hepatology 2004;39:1390-7.

37 Boetticher NC, Peine CJ, Kwo P, et al. A randomized, doubleblinded, placebo-controlled multicenter trial of etanercept in the treatment of alcoholic hepatitis. Gastroenterology 2008;135:1953-60.

38 Mathurin P, Dufour JF, Bzowej N, et al. Selonsertib in combination with prednisolone for the treatment of severe alcoholic hepatitis: a phase 2 randomized controlled trial [abstract]. Hepatology 2018;68:1-183.

39 Mathurin P, Moreno C, Samuel D, et al. Early liver transplantation for severe alcoholic hepatitis. N Engl J Med 2011;365:1790-800.

40 Lee BP, Mehta N, Platt L, et al. Outcomes of early liver transplantation for patients with severe alcoholic hepatitis. Gastroenterology 2018;155:422-30.

41 Lee BP, Vittinghoff E, Hsu C, et al. Predicting Low-Risk for sustained alcohol use after early liver transplant for acute alcoholic hepatitis: the salt score. hepatology, 2018. Available: https://aasldpubs.onlinelibrary.wiley.com/doi/abs/10.1002/hep. 30478 [Accessed 25 Jan 2019]. 